\title{
The addition of Capsicum baccatum to Calabrian monovarietal extra virgin olive oils leads to
}

\section{flavoured olive oils with enhanced oxidative stability}

\author{
Pierluigi Plastina ${ }^{1}$, Rosa Tundis ${ }^{1}$, Chiara La Torre ${ }^{1}$, Vincenzo Sicari ${ }^{2}$, Angelo Maria Giuffré ${ }^{2}$, Alessandro Neri ${ }^{2}$, \\ Marco Bonesi ${ }^{1}$, Mariarosaria Leporini ${ }^{1}$, Alessia Fazio ${ }^{1}$, Tiziana Falco ${ }^{1}$, Monica R. Loizzo ${ }^{1, *}$ \\ ${ }^{1}$ Department of Pharmacy, Health and Nutritional Sciences, University of Calabria, Rende CS, Italy; ${ }^{2}$ Department of \\ Agraria, University "Mediterranea" of Reggio Calabria, Salita Melissari, Feo di Vito, Reggio Calabria (RC), Italy
}

"Corresponding Author: Monica R. Loizzo, Department of Pharmacy, Health and Nutritional Sciences, University of Calabria, 87036 Arcavacata di Rende (CS), Italy. Tel.: +39-0984-493071. Email: monica_rosa.loizzo@unical.it

Received: 24 July 2020 / Accepted: 11 September 2020 / Published: 06 February 2021

(C) 2021 Codon Publications

OPEN ACCESS

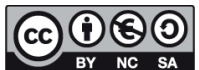

PAPER

\begin{abstract}
This study aimed to evaluate the influence of Capsicum baccatum L. Aji Angelo and Bishop crown cultivars to the quality parameters of flavoured olive oils (FOOs) obtained by the addition of both fresh and dried pepper powders (1\%) to Dolce di Rossano and Roggianella monovarietal extra virgin olive oils (EVOOs). First, pepper extracts were investigated for their total phenolic, flavonoid, carotenoid content as well as phenolic acids, fatty acid profile, and vitamin $\mathrm{C}$ and $\mathrm{E}$ content. In order to evaluate the impact of both fresh and dried peppers on the oxidative stability of FOOs, the Rancimat test was applied. 2,2-Azinobis(3-ethylbenzothiazoline-6-sulfonic) acid (ABTS), 2,2-diphenyl-1-picrylhydrazyl (DPPH), $\beta$-carotene bleaching (B-CB) and ferric reducing antioxidant power (FRAP) assays were used to investigate the antioxidant potential. Bishop crown dried extracts showed the highest phenolic, carotenoid and vitamin content, whereas Aji Angelo had the highest amount of capsaicinoids. Among EVOOs, Roggianella EVOO showed the highest antioxidant activity as well as the highest induction time (39.6 h). Remarkably, FOO obtained by the addition of Bishop crown dried pepper extract to Roggianella EVOO showed a higher induction time $(44.9 \mathrm{~h})$ with respect to the corresponding EVOO.
\end{abstract}

Keywords: antioxidant activity; Capsicum; chemical profile; monovarietal extra virgin olive oil; oxidative stability

\section{Introduction}

According to the definition of the European Union Commission (EC, 2003; EEC, 1991), an extra virgin olive oil (EVOO) must be extracted "only from olives with superior quality, cannot undergo any treatment other than washing the fruits, and decanting, centrifuging and filtering the extracted olive oil. It excludes oils obtained from seeds by chemical or mechanical methods or the use of solvent extraction or re-esterification methods, and those mixed with oils from other sources." Thus, the addition of herbs, spices or other fruits to an EVOO generates a product that cannot be called "extra virgin olive oil," but can be defined as flavoured olive oil (FOO)
(Baiano et al., 2010). These FOOs can be characterised by improved nutritional values, enriched sensory characteristics and increased shelf-life. Recently, several FOOs have been introduced into the market (Issaoui et al., 2016).

Capsicum genus comprises 30 species, however, only five (C. baccatum, C. annuum, C. frutescens, C. chinense and C. pubescens) are those mainly cultivated (Tripodi and Kumar, 2019). Capsicum phytochemicals include phenolics, carotenoids, capsaicinoids and other metabolites (Wahyuni et al., 2013). Several of these compounds are well-known as antioxidants accounting for the traditional use of peppers as food preserving agents from 
ancient times. In the last decades, our research group investigated the chemical composition and bioactivity of many food plants including different Capsicum species collected in Calabria (Southern Italy) (Fazio et al., 2018; Loizzo et al., 2015, 2017; Menichini et al., 2009; Tundis et al., 2013).

This study aimed to evaluate the effect of Capsicum baccatum Aji Angelo and Bishop crown cultivars on the quality parameters of FOOs obtained by the addition of pepper powder to Dolce di Rossano and Roggianella monovarietal EVOOs. For this purpose: (i) total phenolic, flavonoid and carotenoid contents, as well as vitamins $\mathrm{C}$ and $\mathrm{E}$ were assessed in both EVOOs, pepper extracts and FOOs; (ii) fatty acids, sterols, phenolics and capsaicinoids were also quantified; (iii) the protective effect of pepper on FOO oxidative stability; and (iv) the antioxidant potential was investigated by different in vitro methods.

\section{Materials and Methods}

\section{Chemicals and reagents}

All reagents were purchased from Sigma-Aldrich S.p.a. (Milano, Italy), whereas analytical-grade solvents were obtained from VWR International s.r.l. (Milan, Italy). The following standards were used: FAME Mixes-Analytical Standards (CRM47885); Cholesterol (PubChem CID: 5997); 24-Methylene-Cholesterol (PubChem CID: 92113); Campesterol (PubChem CID: 173183); Campestanol (PubChem CID: 119394); Stigmasterol (PubChem CID: 5280794); $\Delta^{7}$-Campesterol (PubChem CID: 5283646); Clerosterol (PubChem CID: 5283638); Clerosterol (PubChem CID: 5283638); $\beta$-Sitosterol (PubChem CID: 222284); Sitostanol (PubChem CID: 6743); $\Delta^{5}$-Avenasterol (PubChem CID: 5281326); $\Delta^{5,24}$-Stigmastadienol (PubChem CID: 286499); $\Delta^{7}$-Stigmastenol (PubChem CID: 3080632); $\Delta^{7}$-Avenasterol (PubChem CID: 12795736); Erythrodiol (PubChem CID: 101761); Uvaol (PubChem CID: 92802); 4-Hydroxybenzoic acid (PubChem CID: 135); $p$-Coumaric acid (PubChem CID: 637542); o-Coumaric acid (PubChem CID: 637540); Ferulic acid (PubChem CID: 445858); Hydroxytyrosol (PubChem CID: 82755); Tyrosol (PubChem CID: 10393); (+) Pinoresinol (PubChem CID: 73399); 3,4-DHPEA-EDA (PubChem CID: 18684078); $p$-HPEA-EDA (PubChem CID: 11652416); Hydroxytyrosol acetate (PubChem CID: 155240); Apigenin (PubChem CID: 5280443); Luteolin (PubChem CID: 5280445); Chlorogenic acid (PubChem CID: 1794427); Quercetin (PubChem CID: 5280343); Beta-carotene (PubChem CID: 5280489); Vitamin C (PubChem CID: 54670067); Vitamin E (PubChem CID: 14985); Capsaicin (PubChem CID: 1548943); Dihydrocapsaicin (PubChem CID: 107982).

\section{Materials, drying process and enrichment procedure}

Dolce di Rossano and Roggianella monovarietal EVOOs were supplied in November 2019 by Frantoio Meringolo, Corigliano Calabro (Cosenza, Italy). All samples have accomplished the UNI10939, 2001 certification. EVOOs were stored in green glass bottles without headspace before analysis. Fruits of C. baccatum Aji Angelo and Bishop crown cultivars were obtained from Miceli s.r.l. farm (Scalea, Cosenza, Italy) that provides its authentication. Fruits were picked up at the maturity stage, defined by a visual colour change and size measurement. Before analyses, fruits were examined for integrity and absence of insect contamination, devoid of peduncles and seeds and cut into small pieces. To obtain dried peppers, fruits were sun-dried at $35^{\circ} \mathrm{C}$ for 2 weeks. Both fresh and dried peppers were grounded and the powders $(50 \mathrm{mg})$ were added to $5 \mathrm{~g}$ of EVOOs and stirred to obtain FOOs that were left for 30 days in the infusion. After that, FOOs were filtered to remove the powder and analysed. Samples were stored at $-20^{\circ} \mathrm{C}$ until analysis.

\section{EVOOs and FOOs}

\section{Quality parameters}

Extra virgin olive oil quality parameters (free acidity, peroxide index, UV light absorption sterol and fatty acid profiles) were analysed according to the EC Regulation methods (EU, 2016). To compare oxidative stability of FOOs and EVOOs, Rancimat equipment (Metrohm, Basel, Switzerland) at $98^{\circ} \mathrm{C}$ and with airflow of $10-12 \mathrm{~L} / \mathrm{h}$ was used, according to a known protocol (Firestone, 1993).

\section{EVOO phenolic extract and high-performance liquid chromatography (HPLC) analysis}

The EVOO phenolic extract was obtained by using a previously described procedure (Montedoro et al., 1992). The obtained extract was dissolved in $1 \mathrm{~mL}$ of methanol/water $(1: 1, v / v)$ and after filtration injected into a high-performance liquid chromatography (HPLC) instrument, Knauer instrument (ASI - Advanced Scientific Instruments, Berlin, Germany), coupled with UV-VIS detector of Waters Company (model Waters 486 Tunable), as previously described (Sicari et al., 2010). The mobile phase was constituted by water/acetic acid $(98: 2, v / v)(\mathrm{A})$ and methanol/acetonitrile $(1: 1, v / v)(\mathrm{B})$, with a flow rate of $1 \mathrm{~mL} / \mathrm{min}$. Data from three independent experiments were acquired with Clarity software (Chromatography Station for Windows) and expressed as mean \pm SD.

Total phenolic, flavonoid, carotenoid and chlorophylls contents Total phenolic content (TPC) was determined as previously described by Gao et al. (2000). The absorbance was 
read at $765 \mathrm{~nm}$. For the total flavonoid content (TFC), the method reported by Yoo et al. (2008) was applied. Absorbance was read at $510 \mathrm{~nm}$. Total carotenoid content (TCC) and chlorophyll content were determined following a previously reported procedure (Mínguez-Mosquera et al., 1900). According to this method, the index K670 assesses the total chlorophylls and their derivatives, whereas the index K470 assesses TCC.

\section{Capsicum baccatum}

\section{Extraction procedure}

Both C. baccatum Bishop crown and Aji Angelo cultivars $(250 \mathrm{~g})$ were subjected to maceration in ethanol $(500 \mathrm{~mL})$ for three times. Extracts were stored until analysis at $-20^{\circ} \mathrm{C}$ in amber bottles.

\section{Total phenolic, flavonoid and carotenoid contents}

Total phenolic content, TFC and TCC were determined as described for EVOO samples in the previous section. TPC was expressed as mg chlorogenic acid (CA) equivalents/100 g dry weight (DW). TFC was expressed as mg quercetin equivalents $(\mathrm{QE}) / 100 \mathrm{~g} \mathrm{DW}$. TCC was expressed as $\mathrm{mg} \beta$-carotene $(\beta C)$ equivalents/100 g DW (Menichini et al., 2009).

\section{Capsaicin and dihydrocapsaicin content}

Capsaicin and dihydrocapsaicin contents were determined according to a previously reported method (Menichini et al., 2009), by using a GC17A gas chromatograph (GC) (Shimadzu, Milan, Italy) equipped with a Flame Ionization Detector (FID). Analyses were performed in isothermal conditions at $210^{\circ} \mathrm{C}$. The capsaicinoids content was done and data are expressed as mean $\pm \mathrm{SD}$ in $\mu \mathrm{g} / \mathrm{g}$ DW.

\section{Vitamin $C$ and $E$ content}

The content of vitamin $C$ in pepper samples was determined according to a previously reported method (Klein and Perry, 1982). For determination of vitamin E content gas chromatography-mass spectrometry (GC-MS) analyses were performed (Loizzo et al., 2015). Vitamin content was expressed as $\mathrm{mg} / 100 \mathrm{~g}$ DW.

\section{Antioxidant activity of EVOOs and pepper extracts}

\section{Radical scavenging activity by ABTS and DPPH tests}

Both 2,2-diphenyl-1-picrylhydrazyl (DPPH) and 2,2-azinobis(3-ethylbenzothiazoline-6-sulfonic) acid (ABTS) tests were applied to examine the radical scavenging activity of Capsicum extracts and EVOO phenolic fraction using the procedure previously described by Leporini et al. (2018). In both cases, ascorbic acid was used as a positive control.

\section{Evaluation of protection of lipid peroxidation}

In the $\beta$-carotene bleaching (B-CB) test, a mixture of linoleic acid (LA), $\beta$-carotene and Tween 20 was prepared and the resulting emulsion was mixed with samples (Loizzo et al., 2019). The absorbance was read after $30 \mathrm{~min}$ of incubation at $470 \mathrm{~nm}$. Propyl gallate was used as a positive control.

\section{Ferric reducing activity power (FRAP) assay}

Both pepper extract and EVOO phenolic fraction (at a concentration of $2.5 \mathrm{mg} / \mathrm{mL}$ ) were tested. Also, the ability of samples to protect the iron from redox reaction is evaluated (Loizzo et al., 2019). Butylated hydroxytoluene (BHT) was used as control.

\section{Calculation of relative antioxidant capacity index (RACl)}

The relative antioxidant capacity index (RACI) was used to establish antioxidant rank of samples (Sun and Tanumihardjo, 2007).

\section{Statistical analysis}

Data were obtained from three different experiments $(\mathrm{n}=3)$ and expressed as means \pm standard deviation (SD). Prism GraphPad Prism version 4.0 for Windows (GraphPad Software, San Diego, CA, USA) was used to calculate the concentration that yielded a $50 \%$ inhibition $\left(\mathrm{IC}_{50}\right)$ value as a result of the concentration-response curve. Pearson's correlation coefficient $(r)$ was calculated using Microsoft Excel 2010 software. ANOVA followed by Dunnett's test $(\alpha=0.05)$ was applied to evaluate the differences between data and positive control result in biological assays, however, Tukey's test was used to determine any significant difference among all treatments at different levels ${ }^{*} \mathrm{P}<0.05,{ }^{* * *} \mathrm{P}<0.01$, ${ }^{* * * * *} \mathrm{P}<0.001$ and ${ }^{* * * * * *} \mathrm{P}$ $<0.0001$.

Principal component analysis (PCA) is the most common form of factor analysis and is categorised as a multivariate statistical technique. It is used to analyse interrelationships among a large number of variables. For the evaluation of the results of the chemical (TFC, TPC, TCC, DPPH, ABTS, $\beta$-carotene-bleaching, FRAP and induction time), analyses of Roggianella and Dolce di Rossano EVOOs and FOOs, PCA was applied.

\section{Results and Discussion}

\section{Dolce di Rossano and Roggianella EVOO quality parameters}

Based on the results reported in Table 1 and according to EC regulation, both Dolce di Rossano and Roggianella EVOOs could be classified as "extra virgin" (EC, 2003; EEC, 1991). 
Table 1. Chemical and qualitative parameters of monovarietal Dolce di Rossano and Roggianella EVOOs produced in Calabria (Italy) during 2018-2019 season.

\begin{tabular}{|c|c|c|c|}
\hline \multirow[t]{2}{*}{ Quality parameter } & \multicolumn{2}{|c|}{ EVOO } & \multirow[t]{2}{*}{ Significance } \\
\hline & Dolce di Rossano & Roggianella & \\
\hline Free acidity (\%) & $0.79 \pm 0.02^{\mathrm{a}}$ & $0.73 \pm 0.01^{b}$ & ** \\
\hline Peroxide value $\left(\mathrm{meqO}_{2} / \mathrm{kg}\right)$ & $15 \pm 1^{\mathrm{a}}$ & $13 \pm 1^{b}$ & ** \\
\hline K232 & $1.9 \pm 0.9^{\mathrm{a}}$ & $1.8 \pm 0.8^{b}$ & ** \\
\hline K270 & $0.15 \pm 0.02^{\mathrm{a}}$ & $0.15 \pm 0.02^{\mathrm{a}}$ & n.s. \\
\hline$\Delta \mathrm{K}$ & $0.001 \pm 0.00^{\mathrm{a}}$ & $0.001 \pm 0.00^{\mathrm{a}}$ & n.s. \\
\hline TPC (ppm) & $73 \pm 2^{b}$ & $537 \pm 6^{a}$ & ** \\
\hline TFC (ppm) & $18 \pm 1^{\mathrm{a}}$ & $15 \pm 1^{b}$ & ** \\
\hline TCC (ppm) & $3 \pm 2^{a}$ & $2 \pm 3^{b}$ & n.s. \\
\hline Chlorophyll (ppm) & $4 \pm 2^{\mathrm{a}}$ & $4 \pm 3^{a}$ & n.s. \\
\hline
\end{tabular}

Our values agreed with those reported by Lavelli and co-workers for EVOO Pendolino, Leccino, Moraiolo and Taggiasca cultivars (Lavelli and Bondesan, 2005).

A significant difference $(\mathrm{P}<0.01)$ was observed between the phytochemicals content (TPC, TFC and TCC) of two investigated oils. In particular, Roggianella EVOO showed a TPC value that was seven-time higher than that found for Dolce di Rossano (Table 1). The TPC value is in line with those found by Sicari et al. (2017) for Roggianella EVOO from Reggio Calabria whereas lower values were recorded for Calabrian Ottobratica and Carolea EVOO, respectively (Piscopo et al., 2016). A statistically significant difference was also observed in TFC with values of 18 and 15 ppm for Dolce di Rossano and Roggianella EVOOs, respectively.

The pigment content of EVOOs is an important quality parameter since consumers directly evaluate it based on their colour (Gargouri et al., 2013). Moreover, their content is strictly related to EVOO stability. As reported in Table 1, TCC and chlorophyll content were not statistically different for Dolce di Rossano and Roggianella EVOOs. This TCC content is similar to that reported by Borrello and Domenici (2019) for Tuscan EVOOs from Frantoio, Leccino, Moraiolo and Pendolino cultivars. Previously, Tuberoso et al. (2016) found chlorophylls values in the range from 6.5 to $10.5 \mathrm{ppm}$, and from 20.9 to $47.6 \mathrm{ppm}$ with respect to TCC for Sardinian EVOOs Semidana and Tonda di Cagliari, respectively.

\section{EVOO chemical profile}

As expected, oleic acid (OA, $\omega-9)$ was the main monounsaturated fatty acid (MUFA) whereas palmitic acid (PA) was the major saturated fatty acid (SFA) in both EVOOs (Table 2). A statistical difference was observed in OA/ LA $(\omega-6)$ ratio $(P<0.01)$, as Roggianella EVOO showed the highest OA/LA ratio, an indicator of the EVOO stability (Alvarruiz et al., 2003). Our data are in line with data found for Roggianella EVOO from Reggio Calabria province (Sicari et al., 2010). More recently, several Italian monovarietal EVOOs including Leccino, Frantoio, Dolce Agogia and Moraiolo were investigated by Blasi et al. (2019). The percentages of OA and PA were quite similar to those found in our samples. Values from 71.84 to $73.20 \%$ and from 16.09 to $19.30 \%$ were recorded for OA and PA, respectively, in Sari Hasebi and Halhali green EVOOs from Turkey (Yorulmaz and Konuskan, 2017).

In general, the sterolic composition of the two investigated EVOOs was significantly different $(P<0.01)$. As expected, $\beta$-sitosterol represented the most abundant phytosterol (Table 3). Two-time higher content of $\Delta^{5}$-avenasterol was found in Roggianella EVOO with respect to Dolce di Rossano. A statistically significant difference in the campesterol/stigmasterol index was observed between investigated EVOOs. Both EVOOs showed values of campesterol lower than $4 \%$, the maximum limit established by European regulations and by the IOC (EU, 2011; IOC, 2009). Our data were in agreement with those reported for Turkish Sari Hasebi and Halhali green EVOOs, that were found in the range from 80.72 to $87.81 \%$ of $\beta$-sitosterol, respectively, followed by $\Delta^{5}$-avenasterol (3.34-5.29\% for Halhali and Sari Hasebi, respectively) (Yorulmaz and Konuskan, 2017). The total sterol content was 1698 and $1971 \mathrm{mg} / \mathrm{kg}$ for Dolce di Rossano and Roggianella, respectively, i.e. much higher than $1000 \mathrm{mg} / \mathrm{kg}$ indicated by the European regulations and by the IOC as a minimum sterol content for an EVOO (EU, 2011; IOC, 2009). 
Table 2. Fatty acid composition of monovarietal Dolce di Rossano and Roggianella EVOOs produced in Calabria (Italy) during 2018-2019 season.

\begin{tabular}{|c|c|c|c|}
\hline \multirow[t]{2}{*}{ Fatty acid } & \multicolumn{2}{|c|}{ EVOO } & \multirow[t]{2}{*}{ Significance } \\
\hline & Dolce di Rossano & Roggianella & \\
\hline Myristic acid (C14:0) & $0.01 \pm 0.00^{\mathrm{a}}$ & $0.01 \pm 0.00^{\mathrm{a}}$ & n.s. \\
\hline Palmitic acid (PA, C16:0) & $14 \pm 2^{\mathrm{a}}$ & $13 \pm 2^{b}$ & ** \\
\hline Palmitoleic acid (C16:1) & $1.3 \pm 0.1^{a}$ & $0.9 \pm 0.1^{b}$ & ** \\
\hline Margaric acid (C17:0) & $0.02 \pm 0.00^{\mathrm{a}}$ & $0.02 \pm 0.00^{\mathrm{a}}$ & n.s. \\
\hline Heptadecenoic acid (C17:1) & $0.04 \pm 0.00^{\mathrm{a}}$ & $0.04 \pm 0.00^{\mathrm{a}}$ & n.s. \\
\hline Stearic acid (SA, C18:0) & $1.4 \pm 0.2^{b}$ & $1.5 \pm 0.1^{\mathrm{a}}$ & ** \\
\hline Oleic acid (OA, C18:1) & $72 \pm 4^{b}$ & $79 \pm 6^{a}$ & ** \\
\hline Linoleic acid (LA, C18:2) & $8.4 \pm 0.9^{a}$ & $6.6 \pm 0.8^{b}$ & ** \\
\hline$\alpha$-Linolenic acid (ALA, C18:3) & $0.40 \pm 0.02^{\mathrm{a}}$ & $0.40 \pm 0.02^{\mathrm{a}}$ & n.s. \\
\hline Arachidic acid (C20:0) & $0.90 \pm 0.03^{\mathrm{a}}$ & $0.80 \pm 0.03^{b}$ & * \\
\hline Gadoleic acid (C20:1) & $0.20 \pm 0.01^{b}$ & $0.30 \pm 0.01^{\mathrm{a}}$ & ** \\
\hline Behenic acid (C22:0) & $0.10 \pm 0.01^{a}$ & $0.10 \pm 0.01^{a}$ & n.s. \\
\hline OA/LA & $8.6^{b}$ & $12.0^{\mathrm{a}}$ & ** \\
\hline$\sum$ SFA & $16.43^{\mathrm{a}}$ & $15.43^{b}$ & ** \\
\hline$\sum M U F A$ & $73.54^{b}$ & $80.60^{\mathrm{a}}$ & ** \\
\hline ¿PUFA & $8.8^{\mathrm{a}}$ & $7.0^{\mathrm{b}}$ & ** \\
\hline MUFA/PUFA & $8.36^{b}$ & $11.51^{\mathrm{a}}$ & ** \\
\hline
\end{tabular}

SFA: saturated fatty acid; PUFA: polyunsaturated fatty acids; MUFA: monounsaturated fatty acids.

${ }^{* *}$ Significance at $P<0.01,{ }^{*}$ Significance at $P<0.05$, n.s. not significant.

Results followed by different letters in the same row are significantly different by Tukey's multiple range test.

Table 3. Sterol composition of Dolce di Rossano and Roggianella EVOOs produced in Calabria (Italy) during 2018-2019 season

\begin{tabular}{|c|c|c|c|}
\hline \multirow[t]{2}{*}{ Sterol } & \multicolumn{2}{|c|}{ EVOO } & \multirow[t]{2}{*}{ Significance } \\
\hline & Dolce di Rossano & Roggianella & \\
\hline Cholesterol (\%) & $0.12 \pm 0.01^{\mathrm{a}}$ & $0.07 \pm 0.02^{b}$ & ** \\
\hline 24-Methylene-Cholesterol (\%) & $0.07 \pm 0.01^{b}$ & $0.29 \pm 0.01^{\mathrm{a}}$ & ** \\
\hline Campesterol (\%) & $2.23 \pm 0.03^{b}$ & $2.67 \pm 0.05^{\mathrm{a}}$ & ** \\
\hline Campestanol (\%) & $0.16 \pm 0.01^{\mathrm{a}}$ & $0.11 \pm 0.01^{b}$ & ** \\
\hline Stigmasterol (\%) & $0.80 \pm 0.02^{b}$ & $1.81 \pm 0.04^{\mathrm{a}}$ & ** \\
\hline$\Delta^{7}$-Campesterol $(\%)$ & $0.08 \pm 0.01^{\mathrm{a}}$ & $0.08 \pm 0.01^{\mathrm{a}}$ & n.s. \\
\hline Clerosterol (\%) & $0.87 \pm 0.01^{b}$ & $0.98 \pm 0.02^{\mathrm{a}}$ & ** \\
\hline$\beta$-Sitosterol (\%) & $88.21 \pm 0.08^{a}$ & $81.71 \pm 0.06^{b}$ & ** \\
\hline Sitostanol (\%) & $0.98 \pm 0.03^{\mathrm{a}}$ & $0.63 \pm 0.02^{b}$ & ** \\
\hline$\Delta^{5}$-Avenasterol (\%) & $5.01 \pm 0.05^{b}$ & $10.3 \pm 0.8^{a}$ & ** \\
\hline$\Delta^{5,24}$-Stigmastadienol (\%) & $0.62 \pm 0.04^{a}$ & $0.51 \pm 0.01^{b}$ & ** \\
\hline$\Delta^{7}$-Stigmastenol (\%) & $0.37 \pm 0.01^{\mathrm{a}}$ & $0.39 \pm 0.05^{a}$ & n.s. \\
\hline$\Delta^{7}$-Avenasterol $(\%)$ & $0.51 \pm 0.01^{\mathrm{a}}$ & $0.43 \pm 0.01^{b}$ & ** \\
\hline Apparent $\beta$-Sitosterol (\%) & $95.68^{a}$ & $94.16^{b}$ & ** \\
\hline Campesterol/Stigmasterol & $2.79^{a}$ & $1.48^{b}$ & ** \\
\hline $\begin{array}{l}\beta \text {-Sitosterol } / \Delta^{5} \text {-Avenasterol } \\
\text { Total sterols }(\mathrm{mg} / \mathrm{kg})\end{array}$ & $\begin{array}{l}17.61^{\mathrm{a}} \\
1698^{\mathrm{b}}\end{array}$ & $\begin{array}{l}7.89^{\mathrm{b}} \\
1971^{\mathrm{a}}\end{array}$ & ** \\
\hline Erythrodiol (\%) & $1.52 \pm 0.02^{\mathrm{a}}$ & $0.92 \pm 0.02^{b}$ & $* \star$ \\
\hline Uvaol (\%) & $0.79 \pm 0.01^{a}$ & $0.16 \pm 0.01^{b}$ & ** \\
\hline
\end{tabular}

All the sterols as well as erythrodiol and uvaol are expressed as percentage of the total sterol content.

${ }^{*}$ Significance at $P<0.01,{ }^{*}$ Significance at $P<0.05$, n.s. not significant.

Results followed by different letters in the same row are significantly different by Tukey's multiple range test. 
Table 4. Phenolic composition of monovarietal Dolce di Rossano and Roggianella EVOOs produced in Calabria (Italy) during 2018-2019 season.

\begin{tabular}{|c|c|c|c|}
\hline \multirow[t]{2}{*}{ Compound } & \multicolumn{2}{|c|}{ Amount in EVOO (ppm) } & \multirow[t]{2}{*}{ Significance } \\
\hline & Dolce di Rossano & Roggianella & \\
\hline 4-Hydroxybenzoic acid & $0.21 \pm 0.01^{b}$ & $0.6 \pm 0.9^{a}$ & ** \\
\hline$p$-Coumaric acid & $0.8 \pm 0.2^{\mathrm{a}}$ & $0.20 \pm 0.02^{b}$ & ** \\
\hline o-Coumaric acid & $0.15 \pm 0.01^{b}$ & $0.24 \pm 0.02^{\mathrm{a}}$ & ** \\
\hline Ferulic acid & $0.27 \pm 0.02^{\mathrm{a}}$ & $0.14 \pm 0.01^{b}$ & ** \\
\hline Hydroxytyrosol & $3.12 \pm 0.03^{a}$ & $2.9 \pm 0.8^{b}$ & ** \\
\hline Tyrosol & $4.04 \pm 0.04^{b}$ & $6.2 \pm 0.5^{\mathrm{a}}$ & ** \\
\hline (+) Pinoresinol & $8 \pm 2^{b}$ & $22 \pm 2^{\mathrm{a}}$ & ** \\
\hline (+) 1-Acetoxypinoresinol & $14 \pm 4^{b}$ & $52 \pm 7^{a}$ & ** \\
\hline 3,4-DHPEA-EDA & $17 \pm 2^{b}$ & $48 \pm 5^{\mathrm{a}}$ & ** \\
\hline$p$-HPEA-EDA & $5.1 \pm 0.9^{b}$ & $18 \pm 1^{a}$ & ** \\
\hline Hydroxytyrosol acetate & $9 \pm 1^{b}$ & $21 \pm 2^{\mathrm{a}}$ & ** \\
\hline 3,4-DHPEA-EA & $3.6 \pm 0.3^{b}$ & $8.26 \pm 0.09^{a}$ & ** \\
\hline$p$-HPEA-EA & $0.87 \pm 0.08^{b}$ & $1.15 \pm 0.01^{a}$ & ** \\
\hline Apigenin & $0.00 \pm 0.00^{b}$ & $0.79 \pm 0.01^{a}$ & ** \\
\hline Luteolin & $0.48 \pm 0.02^{b}$ & $1.12 \pm 0.08^{\mathrm{a}}$ & ** \\
\hline$\sum$ Identified phenolics & $66.64^{b}$ & $178.52^{\mathrm{a}}$ & ** \\
\hline
\end{tabular}

The phenolic composition of both Dolce di Rossano and Roggianella EVOOs is reported in Table 4. In general, the total amount of identified phenolic compounds in the two EVOOs was significantly different $(\mathrm{P}<0.01)$. As expected, secoiridoids and lignans were the most abundant compounds. Roggianella EVOO resulted to be richer in phenolic compounds than Dolce di Rossano. 1-Acetoxypinoresinol followed by 3,4-dihydroxyphenylethanol-elenolic acid dialdehyde (3,4-DHPEA-EDA) were the two most abundant compounds in both EVOOs. The amounts of these compounds in Roggianella were 3.7- and 2.8-times higher than those in Dolce di Rossano. Roggianella EVOO was also characterised by a significant content of pinoresinol and hydroxytyrosol acetate. Dolce di Rossano EVOO variety showed a slightly higher tyrosol content than Roggianella (Table 4). Roggianella EVOO showed a twotimes higher content of luteolin than Dolce di Rossano variety. Among phenolic acids, 4-hydroxybenzoic acid was the main abundant acid in Roggianella oil whereas $p$-coumaric acid was the most abundant in Dolce di Rossano EVOO.

Our data were in line with those previously reported for EVOOs from Roggianella cultivars (Giuffrè and Louadj, 2013). Mean values of 48.54, 38.02 and $16.24 \mu \mathrm{g} / \mathrm{g}$ have been found for 3,4-DHPEA-EDA, 1-acetoxypinoresinol and hydroxytyrosol acetate, respectively. Values in the range $21.11-76.80 \mu \mathrm{g} / \mathrm{g}$ were found for 3,4-DHPEA-EDA in Grignano and Leccino EVOOs (Baiano et al., 2009). The lower content of phenolic compounds has been found in Sardinian EVOOs where 3,4-DHPEA-EDA ranged from 1.0 to $11.6 \mu \mathrm{g} / \mathrm{g}$ in Tonda di Cagliari and Semidana, respectively (Tuberoso et al., 2016). It is interesting to emphasise that 1-acetoxypinoresinol, one of the main phenolics identified in our Calabria EVOO, was not revealed in Tonda di Cagliari and found in a very low quantity in Tonda di Villacidro, Semidana and Bosana oils. However, Bosana contained a high amount of tyrosol $(22.5 \mathrm{ppm})$. A perusal analysis of literature evidenced a great variability in EVOO phenolic profile due to several factors including geographical origin, genetic factors and environmental conditions. This is particularly true for hydroxytyrosol that was found in a high amount in Colozzese EVOO (16.1 ppm), whereas its amount ranged from 0.2 to $8.8 \mathrm{ppm}$ in Spina and Oliva Grossa samples (Negro et al., 2019). With respect to apigenin and luteolin, a higher amount of both phenols were found by Giuffrè et al. (2010) in Roggianella EVOO from Reggio Calabria during the season 2006.

\section{Phytochemical content in C. baccatum cultivars}

Fresh and dried C. baccatum Bishop crown and Aji Angelo fruits were subjected to extraction by maceration. The highest extraction yields were obtained with dried fruits (Table 5). 
Table 5. Investigated Capsicum baccatum cultivars.

\begin{tabular}{llccrr} 
Capsicum baccatum & & Colour & Length $(\mathbf{c m})$ & Width $(\mathrm{cm})$ & Extraction yield (\%) \\
\hline \multirow{2}{*}{ Bishop crown } & Fresh & Red & $5-7$ & $6-8$ & 6.06 \\
\multirow{2}{*}{ Aji Angelo } & Dried & & & $6-8$ & 29.92 \\
& Fresh & Red & $5-7$ & 6.06 & 27.90 \\
\hline
\end{tabular}

Table 6. Total phenolic, flavonoid, carotenoid, capsaicin and dihydrocapsaicin, vitamin $\mathrm{C}$ and vitamin $\mathrm{E}$ content in Capsicum baccatum cultivars.

\begin{tabular}{|c|c|c|c|c|c|}
\hline \multirow[t]{2}{*}{ Content } & \multicolumn{2}{|c|}{ Bishop crown } & \multicolumn{2}{|c|}{ Aji Angelo } & \multirow[t]{2}{*}{ Significance } \\
\hline & Fresh & Dried & Fresh & Dried & \\
\hline $\mathrm{TPC}^{1}$ & $6.80 \pm 0.02^{c}$ & $67 \pm 4^{a}$ & $7.4 \pm 0.4^{c}$ & $63 \pm 2^{b}$ & $* *$ \\
\hline $\mathrm{TFC}^{2}$ & $1.40 \pm 0.03^{c}$ & $10.90 \pm 0.02^{b}$ & $1.10 \pm 0.01^{c}$ & $11.9 \pm 0.2^{\mathrm{a}}$ & ** \\
\hline $\mathrm{TCC}^{3}$ & $2036 \pm 8^{d}$ & $4785 \pm 9^{a}$ & $2763 \pm 7^{c}$ & $3388 \pm 8^{b}$ & ** \\
\hline Vitamin $C^{4}$ & $3.90 \pm 0.22^{b}$ & $5.2 \pm 0.3^{\mathrm{a}}$ & $3.40 \pm 0.09^{c}$ & $4.0 \pm 0.1^{b}$ & ** \\
\hline Vitamin $\mathrm{E}^{4}$ & $5.1 \pm 0.5^{b}$ & $5.3 \pm 0.2^{b}$ & $5.2 \pm 0.4^{b}$ & $5.5 \pm 0.9^{a}$ & $* *$ \\
\hline Capsaicin ${ }^{5}$ & $44 \pm 3^{c}$ & $125 \pm 7^{b}$ & $19 \pm 5^{d}$ & $175 \pm 9^{a}$ & $* *$ \\
\hline Dihydrocapsaicin ${ }^{5}$ & $24 \pm 4^{c}$ & $58 \pm 6^{b}$ & $15 \pm 1^{d}$ & $156 \pm 7^{a}$ & $* *$ \\
\hline
\end{tabular}

${ }^{1}$ TPC: Total Phenolic Content, expressed as mg of chlorogenic acid equivalents/100 $\mathrm{g}$ dried weight (DW), ${ }^{2}$ TFC: Total Flavonoid Content, expressed as mg of quercetin equivalents/100 g DW, ${ }^{3}$ TCC: Total Carotenoid Content, expressed as mg of $\beta$-carotene equivalents $/ 100 \mathrm{~g} \mathrm{DW} .{ }^{4}$ Expressed as mg/g DW, ${ }^{5}$ Expressed as $\mu \mathrm{g} / \mathrm{g}$ DW. Results followed by different letters in the same row are significantly different $\left(P<0.01,{ }^{* *}\right)$ by Tukey's multiple range test.

Dried peppers contained the highest amounts of all analysed phytochemicals. In particular, Bishop crown showed the highest TPC and TCC values whereas Aji Angelo had the highest TFC (Table 6). The same trend was also observed in the extracts obtained from fresh samples.

As reported in Table 6, dried pepper extracts were rich in both capsaicin and dihydrocapsaicin capsaicinoids with values ranging from 58 to $125 \mu \mathrm{g} / \mathrm{g}$ DW for Bishop crown and Aji Angelo dried pepper extract, respectively. Bishop crown dried pepper showed the highest vitamin $\mathrm{C}$ content while vitamin $\mathrm{E}$ was particularly abundant in Aji Angelo dried pepper extract.

\section{Antioxidant activity}

Despite it has been previously reported that antioxidant ability determined by DPPH and ABTS in vitro assays can significantly differ due to different mechanisms of inactivation of the radicals (Antolovich et al., 2002; Plastina et al., 2018), we observed similar trends for the investigated samples. Promising radical scavenging activity was found for Roggianella EVOO phenolic extracts in both applied assays (Table 7). These values are better than that reported for different Calabrian monovarietal EVOOs by Sicari (2017) for Sinopolese and Roggianella and Leporini and co-workers (2018) for Frantoio EVOO (average value of 117.2 and $131.9 \mu \mathrm{g} / \mathrm{mL}$ for ABTS and DPPH, respectively). Previously, Negro and co-workers found $\mathrm{IC}_{50}$ values in the range 91-160 g/oil for DPPH radical scavenging activity for Oliva Grossa and Spina, respectively (Negro et al., 2019). The radical scavenging potential of EVOOs phenolic fraction was positively correlated to TFC and TCC with $r$ values of 1.0.

Among investigated peppers, Bishop crown resulted to be the most active with $\mathrm{IC}_{50}$ values of 148 and $167 \mu \mathrm{g} / \mathrm{mL}$ for DPPH and ABTS tests, respectively. No significant differences between Bishop crown and Aji Angelo dried pepper extracts were evidenced in the protection from lipid peroxidation. Promising ferric reducing ability was observed for both Dolce di Rossano and Roggianella EVOO, respectively. Previously, Loizzo et al. (2017) investigated the antioxidant activity of $C$. annuum and C. chinense fresh and processed peppers and found the highest DPPH radical scavenging potential with Effix fresh pepper sample $\left(\mathrm{IC}_{50}\right.$ value of $\left.3.9 \mu \mathrm{g} / \mathrm{mL}\right)$. A high radical scavenging potential against ABTS has been previously observed for dried C. annuum cv Pellegrino and Idealino samples with $\mathrm{IC}_{50}$ values of 45.2 and $45.7 \mu \mathrm{g} / \mathrm{mL}$, respectively (Loizzo et al., 2017). Great variability in antioxidant potential was observed with oleoresin obtained from different varieties of fresh peppers including 
Table 7. Antioxidant activities of Dolce di Rossano and Roggianella EVOOs and C. baccatum extracts.

\begin{tabular}{|c|c|c|c|c|c|}
\hline Sample & ABTS $^{1}$ & $\mathrm{DPPH}^{1}$ & $\begin{array}{l}\beta \text {-carotene } \\
\text { bleaching }^{1}\end{array}$ & $\begin{array}{c}\text { FRAP } \\
(\mu \mathrm{M} \mathrm{Fe}(\mathrm{II}) / \mathrm{g})\end{array}$ & $\mathrm{RACl}$ values \\
\hline \multicolumn{6}{|c|}{ EVOO phenolic extracts } \\
\hline Dolce di Rossano & $48 \pm 3^{*+1+x}$ & $54 \pm 2^{++1+x}$ & $205 \pm 9^{*+2 * x}$ & $79 \pm 3$ & 71 \\
\hline Roggianella & $36 \pm 1^{+*+3 x}$ & $30 \pm 1^{t+x+t}$ & $127 \pm 5^{t+x+t}$ & $57 \pm 3^{*}$ & -71 \\
\hline \multicolumn{6}{|c|}{ C. baccatum extracts } \\
\hline \multicolumn{6}{|l|}{ Bishop crown } \\
\hline Fresh & $170 \pm 2^{+* * * *}$ & $162 \pm 3^{+\cdots+*}$ & $33 \pm 3^{*+1+}$ & $15 \pm 1^{1+2+*}$ & 0.04 \\
\hline Dried & $167 \pm 3^{n+*+*}$ & $148 \pm 3^{+*+*}$ & $21 \pm 1^{*+*}$ & $14 \pm 2^{+*+1 *}$ & -0.47 \\
\hline \multicolumn{6}{|l|}{ Aji Angelo } \\
\hline Fresh & $453 \pm 4^{*+* * *}$ & $186 \pm 2$ & $77 \pm 3^{*+* * *}$ & $9.1 \pm 0.4^{* *+* *}$ & 0.86 \\
\hline Dried & $256 \pm 4^{* * * *}$ & $157 \pm 3^{* *+*}$ & $20 \pm 1^{* * *}$ & $9.2 \pm 0.8^{* * * * *}$ & -0.43 \\
\hline \multicolumn{6}{|l|}{ Positive controls } \\
\hline Ascorbic acid & $1.71 \pm 0.03$ & $5.0 \pm 0.8$ & & & \\
\hline Propyl gallate & & & $1.00 \pm 0.01$ & & \\
\hline BHT & & & & $63 \pm 4$ & \\
\hline
\end{tabular}

${ }^{1} \mathrm{IC}_{50}$ value $(\mu \mathrm{g} / \mathrm{mL})$. Data are expressed as means \pm S.D. ( $\left.n=3\right)$. DPPH Radical Scavenging Activity Assay, Antioxidant Capacity Determined by Radical Cation $\left(\mathrm{ABTS}^{+}\right), \beta$-carotene bleaching test, Ferric Reducing Antioxidant Power (FRAP). Ascorbic acid, BHT and Propyl gallate were used as positive control in antioxidant tests. Differences within and between groups were evaluated by one-way ANOVA followed by a multicomparison Dunnett's test $(\alpha=0.05):{ }^{* \star * *} P<0.0001,{ }^{* * *} P<0.001$, compared with the positive controls.

C. annuum and C. chinense. The RACI approach was applied to estimate the rank of antioxidant activity for EVOOs and pepper samples. Roggianella EVOO resulted as the most active one whereas Bishop crown dried pepper extract exhibited the highest antioxidant potential among investigated pepper extracts (Table 7).

\section{Protective effect of pepper extracts against oil oxidation}

Rancimat apparatus was used to investigate and compare the stability of EVOOs and the corresponding FOOs (Figure 1). In this method, the oxidation is induced by the passage of constant airflow through the oils that is kept under constant temperature. The volatile products of the reaction are collected in deionised water and are measured through the electric conductivity. During the development of the reaction, due to an increase of the conductivity, a curve is drawn from which the induction period is inferred. Stability was expressed as oxidation induction time (expressed in hours). Roggianella EVOO showed a greater induction time than Dolce di Rossano sample (39.6 versus $19.2 \mathrm{~h}$, respectively). This is probably due to the higher amounts of TPC and identified phenolic compounds found in Roggianella EVOO. In line with our data, the following trend for resistance to oxidation has been previously observed for Calabrian EVOOs: Roggianella $>$ Ottobratica $>$ Sinopolese (Sicari, 2017) and Carolea > Ottobratica > Sinopolese > Grossa di Gerace (Piscopo et al., 2016). Remarkably, all FOOs enriched with pepper extracts had a prolonged induction time with respect to the corresponding EVOO. Among them, FOOs obtained by the addition of Bishop crown dried extract to Roggianella EVOO showed the highest induction time of $44.9 \mathrm{~h}$. This possibly depends on the high amount of bioactive phytochemicals, with the only exception of vitamin $\mathrm{E}$ and dihydrocapsaicin, found in Bishop crown dried extract. Moreover, by considering the protection factor quotient (PF), Bishop crown fresh pepper-FOO had a PF of 5.7 with respect to Dolce di Rossano EVOO followed by FOO obtained by the addition of the dried extract from the same pepper in Roggianella EVOO ( $\mathrm{PF}=$ 5.3). Lower values were observed for FOOs enriched with Aji Angelo extracts with PF values ranging from 1.05 to 3.03 . It has been previously reported that FOOs obtained by the addition of $C$. frutescens extract did not show any protective effect against the oxidation process (Gouveia et al., 2006). This was probably due to the low content of capsaicinoids. By contrary, a protective effect towards oxidation was observed when dried C. annuum pepper was added to EVOO by infusion (10-20\% w/w) up to 30 days (Caporaso et al., 2013). The effect of the addition of spices or their extract/essential oils on oil oxidative stability gained attention by researchers working in the food area. The infusion of dried garlic, oregano and rosemary and hot pepper to Dauno monovarietal EVOO led to FOOs in which the formation of primary oxidation products was reduced without any modification on acidity parameter and secondary oxidation compounds (Gambacorta et al., 2007). More recently, Ayadi 
(a)

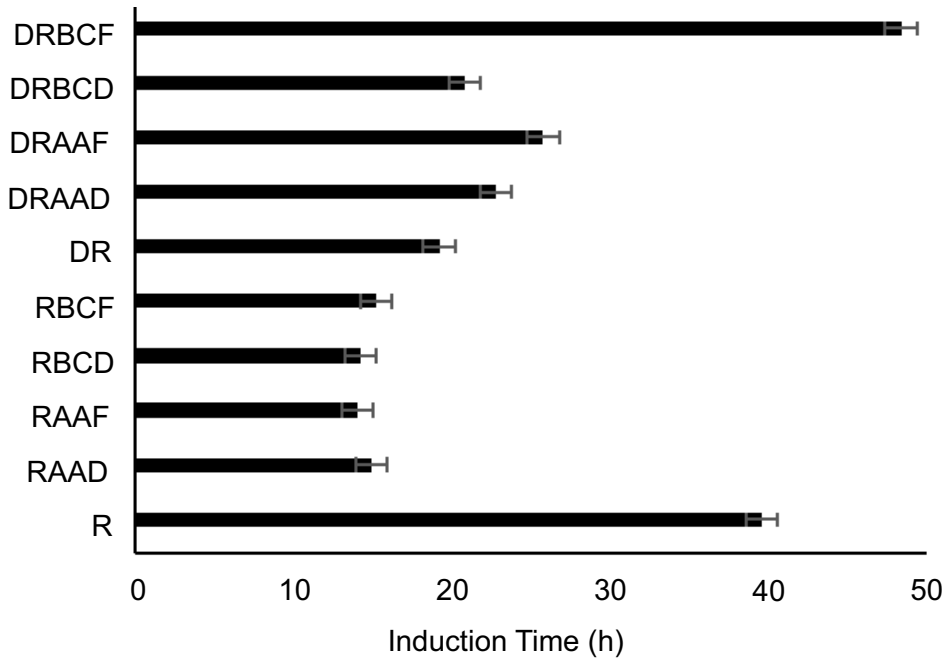

(b)

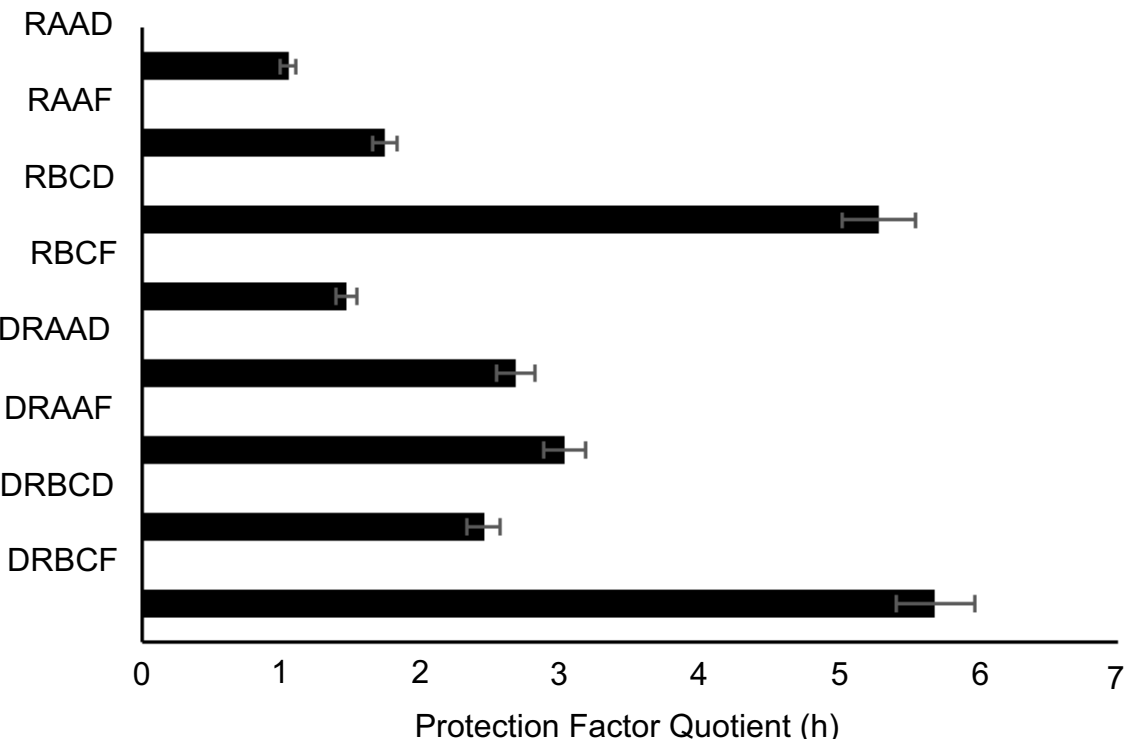

Figure 1. (a) Induction time and (b) Protection Factor quotient of Dolce di Rossano (DR) and Roggianella (R) EVOOs and corresponding FOOs enriched with $C$. baccatum cv Bishop crown (BC) and Aji Angelo (AA) fresh (F) and dried pepper (D) extracts.

et al. (2009) investigated the quality parameters of FOOs obtained by the infusion of $5 \%(w / w)$ of Mediterranean spices to Chemlali EVOO. Although the addition of spices has led to a slight increase in free acidity, an improvement of their thermal resistance and stability with this hierarchy: rosemary $>$ thyme $>$ lemon $>$ basil $\geq$ EVOO control was also observed. This could be caused by the transfer of antioxidant compounds from spices to oil during the infusion. More recently, Ammar et al. (2017) evaluated the effect on quality parameters including oxidative stability of the addition of Opuntia ficusindica flower extracts to "Chemlali" EVOO that results in FOO1 and FOO2 (5 and 15\% ( $w / w)$, respectively). FOO1 was richer in phenolics by $3.4 \%$ than FOO2. In disagreement with our data, this addition did not improve oxidative stability. Also, the induction time obtained by the
Rancimat method showed values of 2.73 and $2.42 \mathrm{~h}$ for FOO1 and FOO2, respectively, in comparison to the control EVOO $(2.83 \mathrm{~h})$. The authors speculated that this may be due to a diffusion of undesirable compounds during the flower maceration of olive oil. These compounds can take part in reactions that negatively interfere with oxidative stability (Ammar et al., 2017).

The unfavourable effect of EVOO aromatisation on oxidative stability was also observed by Sena-Moreno and co-workers who proposed a new EVOO aromatisation method. In this study, liquid-liquid extractions of saffron aqueous extract in "Arbequina" EVOO was done. The sample obtained from the first liquid-liquid extraction was $\mathrm{SO} 1$, whereas $\mathrm{SO} 2, \mathrm{SO} 3$ and $\mathrm{SO} 4$ were those obtained from the second, third and fourth 
extraction, respectively. SO1 showed the highest safranal concentration. It is worthy of mention that in the first seven months, FOOs were characterised by a reduction of quality parameters including oxidative stability. After that FOOs parameters were still comparable to those of EVOO (Sena-Moreno et al., 2018). The impact of enrichment with phenolic compounds from the olive cake and dried thyme on the quality parameters phenolic composition, oxidative stability and antioxidant activity of "Arbequina" EVOO was investigated by Rubió et al. (2012). Flavonoids from thyme were characterised by a higher transference ratio (average $89.7 \%$ ) with respect to secoiridoids from an olive cake (average ratio of 35.3). In each case, all resulted FOOs were more resistant to oxidation with values of induction time of $\sim 8$ and $\sim 20 \mathrm{~h}$ for control and enriched oil, respectively.

\section{Principal component analysis}

The projections of the observations on the first two principal component axes are shown in Figure 2. The accessions are distributed on the factor plane. These two coordinates represent $87.77 \%$ of the total variance (PC1 explained $56.17 \%$ of total variation, while PC2 explained $31.59 \%$ of total variation). The first component (PC1) was positively correlated with TPC, TFC, FRAP, $\beta$-carotene bleaching, RACI and ITDR. The second component (PC2) was positively correlated with TPC, ITDR and ITR. Figure 2 shows the space of oils and hot pepper samples (fresh and dried), samples and the bioactive attributes associated with FOOs. The PCA model showed that FOOs were characterised by a higher induction time than the corresponding EVOOs.

\section{Conclusions}

Flavoured olive oils gained attention by consumers not only as a new dressing for meat, fish or salad but also for the role of spice phytochemicals on human health. In this context, the protective effect of $C$. baccatum peppers cultivars on the oxidative stability of FOOs obtained by the addition of pepper to two Calabrian EVOOs was evaluated. Roggianella EVOO, characterised by a high phytochemicals content showed a longer induction time. The addition of $C$. baccatum Bishop crown to Roggianella EVOO led to a FOO with an increased induction time with respect to the corresponding EVOO. Promising results were also obtained with FOO resulted by the addition of Bishop crown fresh pepper to Dolce di Rossano. Therefore, the addition of C. baccatum Bishop crown peppers was able to enhance the oxidative stability of oils, regardless of the quality of the starting EVOO.

\section{Funding}

This research was funded by POR CALABRIA FESRFSE 2014-2020, Research Project "GLASOIL-Glassa

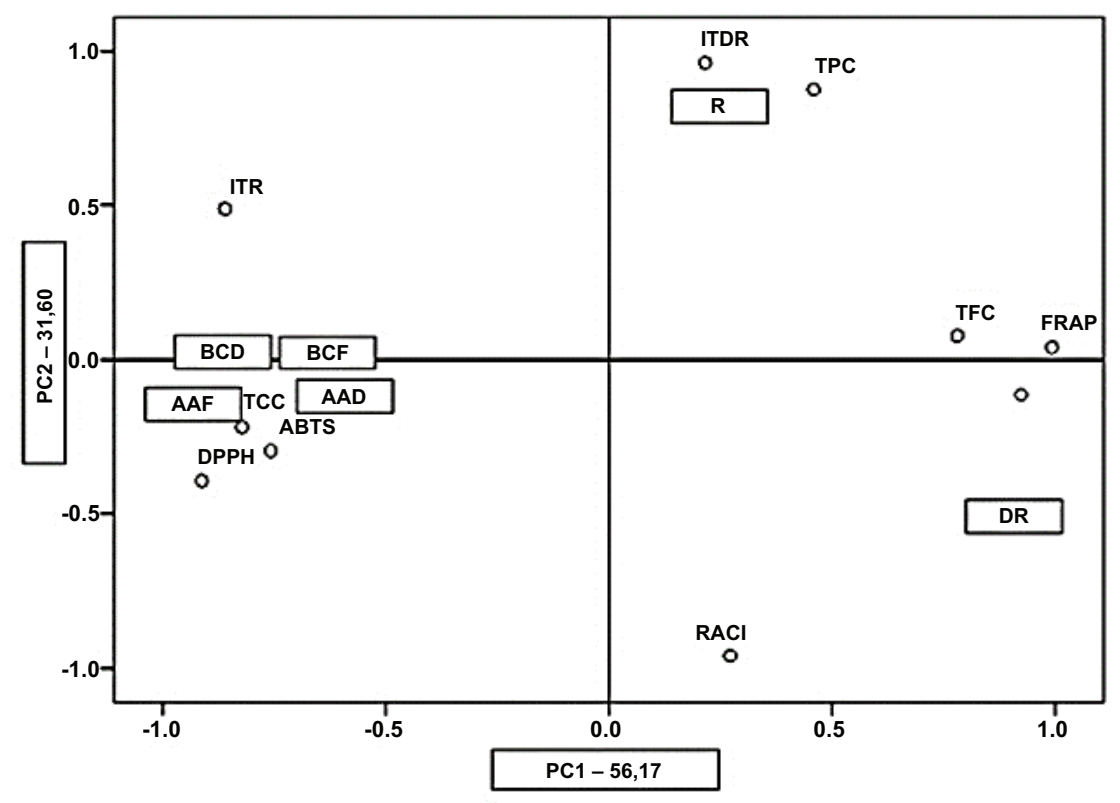

Figure 2. Principal component analysis plot based on bioactivity attributes of extra virgin olive oils (EVOOs) and corresponding flavoured olive oils (FOOs) enriched with C. baccatum pepper extracts. DR: Dolce from Rossano; BCF: Bishop crown Fresh; BCD: Bishop crown dried; AAF: Aji Angelo Fresh; AAD: Aji Angelo dried; R: Roggianella. 
innovativa a base di olio d'oliva" (CUP J77H18000280006). The authors are grateful to Miceli s.r.l., Italy for supplying the pepper fruits and Frantoio Meringolo s.r.l. for supplying "Dolce di Rossano" and "Roggianella" EVOOs.

\section{References}

Alvarruiz, A., Fernández, E., Montero, F., Granell, J. and Pardo, J.E., 2003. Analytical evaluation of "Cornicabra" virgin olive oil from Castilla-La Mancha, Spain. Journal of Food, Agriculture and Environment 1: 48-52. https://doi.org/10.5650/jos.ess15105

Ammar, I., BenAmira, A., Khemakem, I., Attia, H. and Ennouri, M., 2017. Effect of Opuntia ficus-indica flowers maceration on quality and on heat stability of olive oil. Journal of Food Science and Technology 54: 1502-1510. https://doi.org/10.1007/ s13197-017-2581-0

Antolovich, M., Prenzler, P.D., Patsalides, E., McDonald, S. and Robards, K., 2002. Methods for testing antioxidant activity. Analyst 127: 183-198. https://doi.org/10.1039/B009171P

Ayadi, M.A., Grati-Kamoun, N. and Attia, H., 2009. Physicochemical change and heat stability of extra virgin olive oils flavoured by selected Tunisian aromatic plants. Food and Chemical Toxicology 47: 2613-2619. https://doi.org/10.1016/j. fct.2009.07.024.

Baiano, A., Gambacorta, G. and La Notte, E., 2010. Aromatization of olive oil. Transworld Research Network, Trivandrum, India, pp. 1-29.

Baiano, A., Gambacorta, G., Terracone, C., Previtali, M.A., Lamacchia, C. and La Notte, E., 2009. Changes in phenolic content and antioxidant activity of Italian extra-virgin olive oils during storage. Journal of Food Science 74: C177-C183. https:// doi.org/10.1111/j.1750-3841.2009.01072.x

Blasi, F., Pollini, L. and Cossignani, L., 2019. Varietal authentication of extra virgin olive oils by triacylglycerols and volatiles analysis. Foods 8: 58-69. https://doi.org/10.3390/foods8020058

Borrello, E. and Domenici, V., 2019. Determination of pigments in virgin and extra-virgin olive oils: a comparison between two near UV-Vis spectroscopic techniques. Foods 8: 18. https://doi. org $/ 10.3390 /$ foods 8010018

Caporaso, N., Paduano, A., Nicoletti, G. and Sacchi, R., 2013. Capsaicinoids, antioxidant activity, and volatile compounds in olive oil flavored with dried chili pepper (Capsicum annuum). European Journal of Lipid Science and Technology 115: 14341442. https://doi.org/10.1002/ejlt.201300158

Commission Regulation (EU) No 61/2011 of 24 January 2011. Official Journal of the European Union, L 23.

European Union Commission, 2016. Consolidated text on the characteristics of olive oil and olive-residue oil and on the relevant methods of analysis. 01991R2568 - IT - 04.12.2016 - 031.005.

European Union Commission, Regulation CE 1989/2003, 2003. Amending Regulation EEC 2568/91. Official Journal of the European Communities, L 295.

European Union Commission, Regulation EEC 2568/91, 1991. Characteristics of olive and olive-pomace oils and on their analytical methods. Official Journal of the European Communities, L 248.
Fazio, A., Iacopetta, D., La Torre, C., Ceramella, J., Muià, N., Catalano, A., Carocci, A. and Sinicropi, M.S., 2018. Finding solutions for agricultural wastes: antioxidant and antitumor properties of pomegranate Akko peel extracts and $\beta$-glucan recovery. Food \& Function 9: 6618-6631. https://doi.org/10.1039/c8fo01394b

Firestone, D., 1993. Official methods and recommended practices of the American oil chemists' society. 4th ed., American Oil Chemists' Society, Champaign, IL.

Gambacorta, G., Faccia, M., Pati, S., Lamacchia, C., Baiano, A. and La Notte, E., 2007. Changes in the chemical and sensorial profile of extra virgin olive oils flavored with herbs and spices during storage. Journal of Food Lipids 14: 202-215. https://doi. $\operatorname{org} / 10.1111 /$ j.1745-4522.2007.00080.x

Gao, X., Ohlander, M., Jeppsson, N., Björk, L. and Trajkovski, V., 2000. Changes in antioxidant effects and their relationship to phytonutrients in fruits of Sea buckthorn (Hippophae rhamnoides L.) during maturation. Journal of Agricultural and Food Chemistry 48: 1485-1490. https://doi.org/10.1021/jf991072g

Gargouri, B., Ammar, S., Zribi, A., Ben Mansour, A. and Bouaziz, M., 2013. Effect of growing region on quality characteristics and phenolic compounds of chemlali extra-virgin olive oils. Acta Physiologiae Plantarum 35: 2801-2812. https://doi.org/10.1007/ s11738-013-1312-z

Giuffrè, A. and Louadj, L., 2013. Influence of crop season and cultivar on sterol composition of monovarietal olive oils in Reggio Calabria (Italy). Czech Journal of Food Sciences 31: 256-263. https://doi.org/10.17221/136/2012-CJFS

Giuffrè, A.M., Piscopo, A., Sicari, V. and Poiana, M., 2010. The effects of harvesting on phenolic compounds and fatty acids content in virgin olive oil (cv Roggianella). Rivista Italiana Delle Sostanze Grasse 87: 14-23.

Gouveia, A., Duarte, C., Beirão-da-Costa, M., Bernardo-Gil, G. and Moldão, M.M., 2006. Oxidative stability of olive oil flavoured by Capsicum frutescens supercritical fluid extracts. European Journal of Lipid Science and Technology 108: 421-428. https:// doi.org/10.1002/ejlt.200500273

IOC, 2009. COI/T.15/NC n. 3/Rev. 4. November 2009. Trade Standard Applying to Olive Oils and Olive-Pomace Oils, Madrid.

Issaoui, M., Flamini, G., Souid, S., Bendini, A., Barbieri, S., Gharbi, I., Toschi, T.G., Cioni, P.L. and Hammami, M., 2016. How the addition of spices and herbs to virgin olive oil to produce flavored oils affects consumer acceptance. Natural Product Communications 11: 775-780. https://doi.org/10.1177/1934578X1601100619

Klein, B.P. and Perry, A.K., 1982. Ascorbic acid and vitamin A activity in selected vegetables from different geographical areas of the United States. Journal of Food Science 47: 941-945. https://doi. org/10.1111/j.1365-2621.1982.tb12750.x

Lavelli, V. and Bondesan, L., 2005. Secoiridoids, tocopherols, and antioxidant activity of monovarietal extra virgin olive oils extracted from destoned fruits. Journal of Agricultural and Food Chemistry 53: 1102-1107. https://doi.org/10.1021/jf048848k

Leporini, M., Loizzo, M.R., Tenuta, M., Falco, T., Vincenzo, S., Pellicanò, T. and Tundis, R., 2018. Calabrian extra-virgin olive oil from Frantoio cultivar: chemical composition and health properties. Emirates Journal of Food and Agriculture 30: 631637. https://doi.org/10.9755/ejfa.2018.v30.i7.1743 
Loizzo, M.R., Bonesi, M., Serio, A., Chaves-López, C., Falco, T., Paparella, A., Menichini, F. and Tundis, R., 2017. Application of nine air-dried Capsicum annum cultivars as food preservative: micronutrient content, antioxidant activity and foodborne pathogens inhibitory effects. International Journal of Food Properties 20: 899-910. https://doi.org/10.1080/10942912.2016.1188310

Loizzo, M.R., Pugliese, A., Bonesi, M., Menichini, F. and Tundis, R., 2015. Evaluation of chemical profile and antioxidant activity of twenty cultivars from Capsicum annuum, Capsicum baccatum, Capsicum chacoense and Capsicum chinense: a comparison between fresh and processed peppers. LWT-Food Science and Technology 64: 623-631. https://doi.org/10.1016/j. lwt.2015.06.042

Loizzo, M.R., Sicari, V., Tundis, R., Leporini, M., Falco, T. and Calabrò, V., 2019. The influence of ultrafiltration of Citrus limon L. Burm. cv Femminello comune juice on its chemical composition and antioxidant, and hypoglycaemic properties. Antioxidants, 8: 23. https://doi.org/10.3390/antiox8010023

Menichini, F., Tundis, R., Bonesi, M., Loizzo, M.R., Conforti, F., Statti, G., De Cindio, B., Houghton, P.J. and Menichini, F., 2009. The influence of fruit ripening on the phytochemical content and biological activity of Capsicum chinense Jacq. cv Habanero. Food Chemistry 114: 553-560. https://doi.org/10.1016/j. foodchem.2008.09.086

Mínguez-Mosquera, M.I., Gandul-Rojas, B., Garrido-Fernández, J. and Gallardo-Guerrero, L., 1990. Pigments present in virgin olive oil. Journal of the American Oil Chemists' Society 67: 192196. https://doi.org/10.1007/BF02539624

Montedoro, G.F., Servili, M., Baldioli, M. and Miniati, E., 1992. Simple and hydrolyzable phenolic compounds in virgin olive oil. 1. Their extraction, separation and quantitative compounds and semiquantitative evaluation by HPLC. Journal of Agricultural and Food Chemistry 40: 1571-1576. https://doi.org/10.1021/ jf00021a019

Negro, C., Aprile, A., Luvisi, A., Nicolì, F., Nutricati, E., Vergine, M., Miceli, A., Blando, F., Sabella, E. and De Bellis, L., 2019. Phenolic profile and antioxidant activity of Italian monovarietal extra virgin olive oils. Antioxidants 8: E161. https://doi.org/10.3390/ antiox8060161

Piscopo, A., De Bruno, A., Zappia, A., Ventre, C. and Poiana, M., 2016. Characterization of monovarietal olive oils obtained from mills of Calabria region (Southern Italy). Food Chemistry 213: 313-318. https://doi.org/10.1016/j.foodchem.2016.06.080

Plastina, P., Apriantini, A., Meijerink, J., Witkamp, R., Gabriele, B. and Fazio, A., 2018. In vitro anti-inflammatory and radical scavenging properties of Chinotto (Citrus myrtifolia Raf.) essential oils. Nutrients 10: 783-796. https://doi.org/10.3390/ nu10060783

Rubió, L., Motilva, M.-J., Macià, A., Ramo, T. and Romero, M.-P., 2012. Development of a phenol-enriched olive oil with both its own phenolic compounds and complementary phenols from Thyme. Journal of Agricultural and Food Chemistry 60: 31053112. https://doi.org/10.1021/jf204902w

Sena-Moreno, E., Alvarez-Ortí, M., Serrano-Díaz, J., Pardo, J.E., Carmona, M. and Alonso, G.L., 2018. Olive oil aromatization with saffron by liquid-liquid extraction. International Journal of Food Science \& Technology 55: 1093-1103. https://doi. org/10.1007/s13197-017-3025-6

Sicari, V., 2017. Antioxidant potential of extra virgin olive oils extracted from three different varieties cultivated in the Italian province of Reggio Calabria. Journal of Applied Botany and Food Quality 90: 76-82. https://doi.org/10.5073/JABFQ.2017.090.011

Sicari, V., Giuffrè, A., Louadj, L. and Poiana, M., 2010. Evolution of phenolic compounds of virgin olive oil during 12 months storage. Rivista Italiana Delle Sostanze Grasse 87: 109-116.

Sun, T. and Tanumihardjo, S.A., 2007. An integrated approach to evaluate food antioxidant capacity. Journal of Food Science 72: 159-165. https://doi.org/10.1111/j.1750-3841.2007.00552.x.

Tripodi, P. and Kumar, S., 2019. The Capsicum crop: an introduction. In: Ramchiary, N. and Kole, C. (eds.) The capsicum genome. Compendium of plant genomes. Springer, New York, USA pp. 1-8.

Tuberoso, C.I.G., Jerković, I., Maldini, M. and Serreli, G., 2016. Phenolic compounds, antioxidant activity, and other characteristics of extra virgin olive oils from Italian autochthonous varieties Tonda di Villacidro, Tonda di Cagliari, Semidana, and Bosana. Journal of Chemistry 2016: 8462741. https://doi. org/10.1155/2016/8462741

Tundis, R., Menichini, F., Bonesi, M., Conforti, F., Statti, G., Menichini, F. and Loizzo, M.R., 2013. Antioxidant and hypoglycaemic activities and their relationship to phytochemicals in Capsicum annuum cultivars during fruit development. LWT-Food Science and Technology 53: 370-377. https://doi. org/10.1016/j.lwt.2013.02.013

Wahyuni, Y., Ballester, A.-R., Sudarmonowati, E., Bino, R.J. and Bovy, A.G., 2013. Secondary metabolites of Capsicum species and their importance in the human diet. Journal of Natural Products 76: 783-793. https://doi.org10.1021/np300898z

Yoo, K.M., Lee, C.H., Lee, H., Moon, B.K. and Lee, C.Y., 2008. Relative antioxidant and cytoprotective activities of common herbs. Food Chemistry 106: 929-936. https://10.1016/j. foodchem.2007.07.006

Yorulmaz, H.O. and Konuskan, D.B., 2017. Antioxidant activity, sterol and fatty acid compositions of Turkish olive oils as an indicator of variety and ripening degree. International Journal of Food Science \& Technology 54: 4067-4077. https://doi.org/10.1007/ s13197-017-2879-y 